\title{
The special principles of development of the corporate information system for hi-tech products
}

\author{
Ekaterina Yurievna Vinogradova ${ }^{1, *}$, Anna Igorevna Galimova ${ }^{1}$, and Svetlana Leonidovna \\ Andreeva $^{1}$ \\ ${ }^{1}$ Ural State University of Economics, Ekaterinburg, Russia
}

\begin{abstract}
In article describes the problem of lack of accounting of specifics of production and estimation of cost of hi-tech production at development and deployment of a corporate information system. Creation of Hi-Tech products on the basis of application of unique productions demands special approach to assessment of their cost that results in impossibility of direct transferring of the existing models to practice of their activity. Authors offer the special principles of creation of a corporate information system by production of hi-tech production taking into account its features. Such approach will allow to carry out the most exact forecasting of cost of production at a stage of its planning and also positive influence of use of the offered principles on efficiency of use of financial resources of the enterprises for production of hi-tech production is noted.
\end{abstract}

\section{Introduction}

In the conditions of global economic instability increase in production efficiency of hi-tech production is a subject of interest of many countries as allows to get competitive advantage in various branches. In the Russian Federation from the state budget considerable financial resources are allocated for creation of hi-tech production within implementation of the planned documents developed by the ministries and departments [3, page 164]. At a stage of planning evaluating cost of research and development on creation of new samples of hitech production for forecasting of their effectiveness is necessary. The basic principles of estimation of cost of production are given in article 40 of the Tax Code of the Russian Federation. Characteristics of identification of market price concern them. In case determination of market price becomes impossible due to the lack of goods, works or services in the corresponding market or identical production, the expensive method by identification of the expected production expenses and profit, usual is applied to this field of activity [1]. Generally listed principles form the basis of estimation of cost of production during creation of a corporate information system.

\footnotetext{
* Corresponding author: katerina@usue.ru
} 


\section{Design and development of corporate information systems}

Production of hi-tech production has unique and rather labor-consuming character and demands considerable financial resources. Therefore, for improvement of methodical ensuring estimation of cost of hi-tech production and also for giving of complete character and practical orientation to him when developing an information system needs to add the following special principles of innovative development of economy:

1. At estimation of cost of realization of the sample of hi-tech production planned to creation the cost of achievement of the set effect with use of the existing sample has to be considered. When forming an information system, it is necessary to consider that the perspective sample of hi-tech production competes with the existing sample for the right of the purchase. The effect of application of such samples and expenses, necessary for achievement of this effect, act as the indicators defining competitiveness of alternative samples.

2. For justification of cost of an action it is necessary to introduce the block of assessment of efficiency of use of financial resources. For the purpose of ensuring economic security of the state and competition with the foreign companies it is necessary to reach higher characteristics of domestic samples in comparison with the existing samples. It will demand considerable financial resources, and at the same time, will allow to reach the high level of effect of their application. Therefore, the customer will need validity of cost of creation of a sample as growth of its cost directly depends on improvement of characteristics. Continuous comparison of expenditure of financial resources with the established top limit price which excess becomes inexpedient from the technical and economic point of view is also necessary [6-16].

3. In case of specification of cost of actions which pass to new planning period the information system has to consider only the forthcoming expenses, since the moment of the beginning of new planning period. As creation of complex hi-tech products can take more than five years, it is impossible to predict authentically costs of its creation because of probable difficulties in the solution of difficult and unique tasks of scientific and technical and production and technological character. Changes of market condition and requirements to its characteristics and consumer properties [2 exert impact on the level of cost of hi-tech production, with. 33]. At assessment of expenses on realization of actions in planning period the system should not consider already made expenses as there are no alternative options of their use, and they do not treat planning period.

4. The cost of an action for creation of complex hi-tech products should be split up on several blocks of cost of its components. Application of this function of a corporate information system is necessary in case of existence of difficult technical systems of big dimension, for example, of aviation, space or missile systems which consist of diverse subsystems. It is important to note essential differences of such subsystems in design-layout decisions, their creation will require attraction of considerable financial resources, and also holding a separate competition in each of them is possible. Therefore, estimation of cost not only hi-tech production in general, but also its compound subsystems will promote increase in objectivity of definition of the budgetary expenses on creation of a sample.

5. Introduction of a possibility of application of the basic data of alternative approaches to estimation of cost of the planned actions for creation of hi-tech production differing from each other in volume. It is necessary to develop a complex of methods of assessment of cost indexes of actions for creation of production, providing such choice within one information system will allow to reveal optimum approach to estimation of cost of a concrete sample [720].

6. On complete actions cost indexes have to be automatically brought to a comparable form. Because the changing macroeconomic conditions exert impact on realization of 
actions for creation of hi-tech production, when comparing the cost of complete actions has to be specified to uniform timepoint with application of indexes deflators [21-27].

\section{Results}

The financial structure has to correspond to kinds of activity of the company. This approach will allow to estimate results of activity of the enterprise for each direction having the budgets, having provided their effective management.

Integral part of the software product is creation of structurally functional model of the solution of problems of planning and management with differentiation of business processes.

Processes are classified on the main and auxiliary. The main processes create new quality of production. Auxiliary processes create infrastructure of the enterprise. The person, responsible for process, has the right to change and improve it and is the owner of process. Borders of process are defined by an interval from the moment preceding the first operation (border of "entrance") and till the moment following the last operation (border of "exit").

The interface of process represents the organizational, technical and information mechanism when which using the interrelation between processes is carried out. Therefore, optimization of activity of the enterprise has to be organized business around - processes for the purpose of overcoming their fragmentariness for achievement of considerable improvements of key indicators therefore the main objective of creation of the process focused enterprise is allocation business - processes according to grocery lines and functional divisions with their subsequent connection in through processes which are aimed at creation of different types of production.

Each company represents difficult socially - technical system. The concept "system" used in modern practice, has a set of semantic nuances and values. In this regard it is necessary to define the values directly related to the system analysis of activity of the enterprise. The most suitable definitions are given below.

The system has the following integrative properties:

- the variety and distinction of components is connected with their functional specificity and autonomy;

- the properties which are absent in separately taken components can be present at system in general;

- structure that means existence established interrelations and the relations between system components, their distribution on hierarchy levels.

Opposition of system to an environment or Wednesday is its initial characteristic. Everything that is outside system belongs to Wednesday. Wednesday is a set of all systems except for the studied part of the world around. In this regard it is possible to draw a conclusion that the system represents the final set of objects allocated from the environment by delimitation of system. Between the external environment and the enterprise there is a large number of interrelations which are the instrument of interaction of system and Wednesday. Exchange of material, financial, power, information and other elements between system and is made Wednesday by means of mutual transfer on entrance and output communications. Resources are elements which are transferred to system from the environment, and end products of activity of system - elements which the system transfers to the external environment.

Achievement and maintaining desirable result of behavior of system acts as its main objective. Interpretation of the purpose of system in relation to the enterprise - aspiration to optimum result which represents maximizing value of the capital on condition of constant 
preservation of the established liquidity level, achievement of the goals of production and realization taking into account social tasks.

The main objective of system is the description of a way of achievement of the goal fixed by the expected numerical characteristics. The set of the interconnected purposes represents their system. It is possible to allocate several classifications of systems of the purposes which treat:

- short-term (performance in a year or earlier) and long-term (performance through the period exceeding 1 year) the purposes;

- tactical and strategic objectives;

- financial, production, social purposes, improvement of quality of production and others.

\section{Conclusion}

In conclusion it should be noted that the implementation of a complex of the offered principles will allow to consider specifics of the enterprises for production of hi-tech production from the enterprises of other types of industrial production at development and deployment of a corporate information system.

\section{References}

1. E.Yu. Vinogradova, Technologies for using neuromodels for solving production management problems, Research the development and application of high technology in industry, 55-56. (SPbGPU, 2008)

2. E.Yu. Vinogradova, A.I. Galimova, Journal of Ural State University of Economics, 2 (70), 111-123 (2017)

3. E.Yu. Vinogradova, Technologies for using neural networks for solving production management problems, Research the development and application of high technology in industry, 13-14. (SPbGPU, 2008)

4. E.Yu. Vinogradova, Applied Informatics, 1 (37), 122-132 (20125.

5. V.G. Tsaregorodtsev, A look at the architecture and requirements for a neuroimulator for solving modern industrial problems, Neuroinformatics and its Applications, 171175 (Krasnoyarsk, 2003).

6. D.E. Behstens, V.M. Van Den Berg, D. Wood Neural networks and financial markets. Making decisions in trading operations (TVP Scientific Publishing House, M.)

7. S. Khaikin, Neural networks. Full course (M. Williams, 2006)

8. A.N. Hunchback, Methods of neuroinformatics. The collection of scientific works edited by the doctor of physical and mathematical sciences (Krasnoyarsk, KSTU, 1998)

9. E.A. Alexandrova, S.A. Anikin, Bulletin of the South Ural State University. Series: Mathematical Modeling and Programming, 4 (7), 22-35 (2014)

10. V.K. Belyaev, Economic evaluation of management decisions Economic evaluation of management decision, 310 (Irkutsk: Publishing House of BSUEP, 2013)

11. E.V. Vodopyanova, Modern Europe, 2 (58), 31-41 (2014)

12. T.Yu. Goraeva, L.K. Shamina, Scientific and Technical Sheets of St. Petersburg State Polytechnic University. Economic sciences, 3 (221), 198-210 (2015)

13. N.I. Komkov, N.N. Bondareva, V.S. Romantsov, N.I. Didenko, D.F. Skripnyuk, Methodological and organizational fundamentals of company development management, 520 (M.: LLC Publishing House "Science", 2015)

14. S.S. Kritskaya, Economic analysis: theory and practice, 4 (451), 107-121 (2016) 
15. T.E. Kuznetsova, L.V. Nikiforov, Issues of state-municipal and municipal government, 2, 51-64 (2013)

16. N.A. Lyapkina, A.V. Zharikova, Problems and prospects of economic development, 7, 409-413 (2014)

17. O.Yu. Martynov, News of higher educational institutions. North Caucasus region. Series: Engineering, 2, 128-131 (2012)

18. T.N. Marshova, L.E. Protasova, T.N., Collection of scientific works of IMEI, 2, 106$131(2015)$

19. A.I. Mnogogreshnov, S.M. Samokhvalova, Actual problems of aviation and astronautics, 11, 715-717 (2015)

20. T.A. Nikolenko, Yu.A. Zobnin, Economics and Entrepreneurship, 4-1 (69-1), 45-48 (2016)

21. A.I. Popov, News of St. Petersburg University of Economics and Finance, 4, 18-26 (2012)

22. O.N. Sukhanova, O.V. Mentyukova, Models, systems, networks in economics, technology, nature and society, 1 (17), 125-134 (2016)

23. Typical guidelines for planning, accounting and calculating the cost of scientific and technical products. Standard guidelines for planning, accounting and calculating the cost of scientific and technical products. (dated 15.06.1994 № OR-22-2-46)

24. A.V. Fomina, B.N. Avdonin, A.M. Batkovsky, M.A. Batkovsky Management of the development of high-tech enterprises of high-tech industries

25. E.Yu. Vinogradova, S. L. Andreeva, A. V. Babkin, A. I. Galimova. Strategic Partnership of Universities and Enterprises of High-Tech Industries (Science. Education. Innovation), 63-66 (2017) doi: 10.1109/IVForum.2017.8246052

26. E.Yu. Vinogradova, A.I. Galimova, N.V. Mukhanova, S.L. Andreeva Lecture notes in the field of computer science (including subseries Lecture notes in the field of artificial intelligence and Lecture notes in the field of bioinformatics), 10531 LNCS, 337-350 (2017) doi: 10.1007 / 978-3-319-67380-6_31

27. V.V. Prokhorova, A.A. Adamenko, V.A. Tupchienko, V.V. Shalatov, S.A. Vasnev, V.A. Blaginin, International Journal of Applied Business and Economic Research, 15(12), 225-232 (2017) 